\title{
„STULTIFERA NAVIS« NA BALKANSKI BEGUNSKI POTI
}

\author{
Darja ZAVIRŠEK'
}

COBISS 1.01

\section{IZVLEČEK}

\section{"Stultifera Navis« na balkanski begunski poti}

Zbirni in namestitveni centri za begunce, azilni domovi in centri za tujce so sodobna oblika institucionalizacije in prostorske segregacije ljudi. Nekoč dobro znani procesi "velikega zapiranja«, biopolitike in ustvarjanja "populacij« so danes prežeti z ideologijami evrocentrizma, kulturalizacije in kulturnega rasizma, ki jih širijo mediji. Primerjava s procesi zapiranja hendikepiranih pokaže, da so se po eni strani procesi deinstitucionalizacije na Zahodu uspešno končali ali pa še potekajo (v Sloveniji, na primer), po drugi strani pa se povsod po Evropi krepi institucionalizacija beguncev in migrantov. Namesto konstruiranja beguncev kot varnostne grožnje, zdravstvenega tveganja in kulturne drug(ačn)osti so potrebni ukrepi deinstitucionalizacije in depatologizacije begunskih življenj. KLJUČNE BESEDE: begunci, evrocentrizem, biopolitika, »balkanska begunska pot«, deinstitucionalizacija

\section{ABSTRACT}

\section{"Stultifera Navis" on the Balkan Refugees Route}

Collection centres and hot spots, asylum and detention centres for refugees are forms of institutionalisation and spatial segregation of people. The well-known processes of the "big confinement", biopolitics and the creation of "populations" are today pervaded with the ideologies of eurocentrism, culturalisation and cultural racism produced by the media. Compared with the processes of spatial segregation of the disabled in the past, one can conclude that while the deinstitutionalisation was achieved in the west and is in some countries on its way (in Slovenia for example), the institutionalisation of migrants and refugees takes place across Europe. Instead of the construction of the refugees as the national threat, health risk and the cultural Other, the measures of deinstitutionalisation and depathologisation of the refugees' lives are needed.

KEY WORDS: refugees, eurocentrism, biopolitics, "Balkan refugee route", deinstitutionalisation

Dr. sociologije, redna profesorica; Univerza v Ljubljani, Fakulteta za socialno delo, Topniška 31, SI-1000 Ljubljana; Darja.zavirsek@fsd.uni-lj.si 


\section{UVOD}

Čeprav se je število migrantov, ki so v Evropo prihajali z Bližnjega vzhoda, iz Afrike in srednje Azije, povečevalo vse od leta 2000, se Slovenija, z izjemo nekaterih kritičnih raziskovalk in novinarjev (Pajnik, Lesjak Tušek, Gregorčič 2001; Kralj 2005; Zorn 2008), s to tematiko ni ukvarjala vse do leta 2015, do nastanka t. i. »balkanske begunske poti«. Ta je po tem, ko so nekatere države EU odprle meje za prihod večjega števila migrantov, delovala kot koridor množičnih prehodov. Tako so sredi leta 2015 migranti in begunci v Sloveniji in še v nekaterih drugih postsocialističnih državah postali eno najaktualnejših političnih in družbenih vprašanj. Če je sprememba najprej povzročila osuplost nad množicami ljudi, ki so $\mathrm{z}$ vlaki, avtobusi in peš prestopali meje, pa je jeseni $2015 \mathrm{v}$ teh državah naivno osuplost ${ }^{2}$ zamenjala militarizacija meja in jasneje izražena ksenofobija večinske populacije. Madžarska je že spomladi 2015 na meje s Srbijo in Hrvaško poslala vojake, policiste in zapornike, ki naj bi zadrževali begunce, kmalu za tem pa je na obeh mejah in tudi na meji s Slovenijo začela postavljati zidove in bodeče žice. »Balkanska begunska pot» se je preusmerila proti Sloveniji, pred bežečimi ljudmi pa se je pojavilo več meja (grška, makedonska, srbska, hrvaška, slovenska). Kmalu po Madžarski so začele tudi Makedonija, Hrvaška in Slovenija meje militarizirati z vojaki in $s$ »tehničnimi ovirami«. ${ }^{3}$ Čeprav sta Nemčija in Avstrija pokazali veliko humanitarne naravnanosti, saj sta sprejeli in na zgleden način poskrbeli za veliko število beguncev ( $\mathrm{s}$ takojšnjo vključitvijo otrok $\mathrm{v}$ šole, mladih $\mathrm{v}$ oblike poklicnega vajeništva in $\mathrm{v}$ študijski proces, manjše število ljudi razpršili po mestih in širili strpnost in zmerno dobrodošlico), sta obenem proti koncu leta 2015 tudi ti državi iskali načine, da bi ljudi zadržali zunaj meja, in sicer tako, da sta pritisnili na schengenske države, naj meje Evrope čim bolj zaprejo. Tako je bil eden od argumentov militarizacije meja v Sloveniji, da bo država, ki jih ne bo varovala, izključena iz schengenskega režima.

$\mathrm{Na}$ balkanski begunski poti, pretežno ob državnih mejah, so začeli odpirati zbirne centre, eno od sodobnih oblik institucionalizacije in prostorske segregacije ljudi. Za analizo procesov »transferja« beguncev čez Slovenijo uporabljam Goffmanovo teorijo totalne ustanove ter Foucaultovo teorijo biopolitike in sortiranja populacije (Goffman 1957, 1961; (Foucault 2006 [1961], 1980, 2015 [2004]). Nekdanje medicinsko-zaporniške institucije za zapiranje norcev, "posebnežev«, "moralno vprašljivih" in hendikepiranih so danes primerljive s centri za tujce, z zbirnimi centri (zidanimi stavbami in postavljenimi šotori), ki so prostorsko ločeni od večinskega prebivalstva, ljudje v njih pa segregirani, policijsko nadzorovani in pogosto razčlovečeni. ${ }^{4}$ Konstruiranje beguncev kot varnostne grožnje, zdravstvenega tveganja (kužnosti) in kulturne drug(ačn)osti je, kot nekoč v primeru norcev in telesno in socialno hendikepiranih, ki so prav tako funkcionirali kot "grožnja» in »nevarnost« za večinsko prebivalstvo, danes proizvedeno z načinom sprejema (policijsko

1 Dr. Jelki Zorn se zahvaljujem za dragocene sugestije med pisanjem članka.

2 Vojna v Siriji poteka že od leta 2011.

3 Septembra 2015 je Slovenija na mejo s Hrvaško namestila specialno enoto policije, oktobra 2015 je vlada potrdila novelo zakona o obrambi, s katerim je vojska dobila del policijskih pooblastil, od Madžarske pa kupila rezilno in bodečo žico. Sredi novembra 2015 je Slovenija začela postavljati žičnato ograjo na meji s Hrvaško, Makedonija pa je začela ograje postavljati na meji z Grčijo.

4 V mislih imam predvsem dolgotrajno bivanje $\mathrm{v}$ segreriranih namestitvah in ne neobhodno čakanje na registracijo. 
spremljanje ljudi, ki bežijo; policijski sprejem in odločitve, kdo gre čez mejo in kdo ostane; policijsko določanje, kdo je na vrsti za določen postopek) in s procesom obravnave (zapiranje, discipliniranje, ustvarjanje nevidnosti ipd.).

Kritična analiza ravnanja $z$ ljudmi, ki bežijo pred vojnami, družinskimi ozemeljskimi spori, preganjanjem zaradi osebnih okoliščin (istospolno usmerjeni; tisti, ki jim preti krvno maščevanje itd.) in ekonomsko bedo, ki jo povzročajo neoliberalizem, okoljevarstvene katastrofe, etnični konflikti, sektaški boji, paravojaške organizacije in mednarodna vojaška posredovanja, je namenjena argumentiranju tega, da na humanitarno krizo ne moremo in ne smemo odgovoriti s krizo humanosti, temveč $\mathrm{z}$ deinstitucionalizacijo procesov sprejemanja beguncev v evropskih državah, depatologizacijo in demilitarizacijo njihovih življenj ter $\mathrm{z}$ univerzalnimi humanističnimi vrednotami.

Kritična primerjalna analiza procesov upravljanja migracij danes, medijska analiza pisanja o migracijah med septembrom in decembrom 2015 in diskurzivna analiza terenskih poročil ter njihova analitična refleksija so metodologija pričujočega članka.

\section{KULTURALIZACIJA IN EVROCENTRIZEM}

Postsocialistične države, ki jih uvrščamo med t. i. balkanske (Romunija, Hrvaška, Slovenija itn.), pa tudi tiste, ki so del postsocialistične »Evrope« (Madžarska, Poljska, Slovaška, Češka), so na migrante reagirale $\mathrm{z}$ državnim nacionalizmom in novimi skrajno desnimi gibanji in političnimi strankami. Nekatere države, kot na primer Madžarska in Slovaška, so se uradno uprle odločitvi Evropske komisije, da sprejmejo določeno število beguncev po načelu kvot znotraj držav EU, ${ }^{5}$ ali pa so kvote pogojevale. Slovaška je odločila, da sprejme le družine krščanske veroizpovedi in ne posameznikov, slovenska vlada pa je izrazila interes, da med »kvotnimi begunci« sprejme družine, angleško govoreče osebe in pismene ljudi. Paradoks je, da je zavračanje beguncev najmočnejše v tistih državah, kjer jih je najmanj, kar spominja na sovraštvo do Judov v 19. in 20. stoletju, ki je bilo razširjeno tudi tam, kjer jih skorajda ni bilo in ga poznamo kot »antisemitizem brez Judov« (na Japonskem, v Sloveniji ipd.). Slovenija je imela julija 2016 zgolj 612 prošenj za mednarodno zaščito, le 58 ljudem pa je država odobrila prošnjo za azil, kar kaže na razkorak med moralno paniko in številom ljudi, ki so ostali v Sloveniji.

Večinsko zavračajoč odnos do migrantov, ki je od odprtja »balkanske begunske poti« značilen predvsem za postsocialistične države in je hkrati širši vseevropski fenomen, je posledica kulturalizacije Drugega. Samir Amin (2009) jo je povedno analiziral kot evrocentrizem, utemeljen na ideji o kontinuiranem zgodovinskem razvoju Evrope vse od grške civilizacije, njegovi glavni manifestaciji pa sta krščanstvo in kapitalizem. Medtem ko naj bi si vzhodnjaška metafizika prizadevala odkriti najvišje načelo ali »absolutno resnico«, se je evropska civilizacija usmerila v racionalnost in iskanje delnih resnic, kar naj bi spodbudilo prehod $\mathrm{v}$ kapitalizem in posledično demokracijo. Jedrni del evrocentrizma je islamofobija.

$5 \quad$ Madžarska vlada je želela $\mathrm{z}$ referendumom 2. oktobra 2016 zagotoviti podporo vladni politiki zavračanja prerazporeditve beguncev po državah Evropske unije, a je bil referendum neveljaven, saj se ga je udeležilo manj kot 50 odstotkov volilnih udeležencev. 
Slovenska desno usmerjena tiskana medija, dnevnik Slovenske novice in tednik Reporter, kar najbolje izkazujeta Aminovo idejo evrocentrizma. ${ }^{6}$ Domnevne esencialne značilnosti Evropejcev, ki se kažejo v navadah, vrednotah in celo čustvovanju ljudi, naj bi bile povsem drugačne od tistih, ki jih imajo migranti: "prizori, ki jih v naši kulturi težko razumemo«; »kako pripravljeni so prihajajoči muslimani na sožitje z našo evropsko kulturo«; »v tretjem svetu ni razvitega občutka hvaležnosti, nasploh so občutki zelo slabo razviti« itd. Medijsko poročanje je ustvarilo podobo kulturno povsem drugačnih ljudi, ki prihajajo v Evropo: »[...] kupi reči, ki so jih begunci odmetavali kar med potjo; še zaprte ribje konzerve, odeje in folije, vreče s hrano (Šuljić 2015a); »v tretjem svetu ni razvitega občutka hvaležnosti, nasploh so občutki zelo slabo razviti - nadomesti jih občutek samodejnosti ali brezobčutek, dosega cilja z vsemi sredstvi, igra, izraba, zloraba. Človek tretjega sveta je izredno pragmatičen. Ne ovirajo ga čustva, ne ovirajo ga moralna vprašanja« (Preac 2015).

Amin (2009: 63) pokaže, da evropska identiteta temelji na mitih, kot je tisti o evropski kontinuiteti z grško kulturo, iz katere so izbrisani vsi "vzhodnjaški« vplivi, mit o krščanstvu kot evropski religiji ${ }^{7}$ ter mit o evropski zgodovini, ki naj bi nujno vodila v razcvet kapitalizma. Evropska identiteta naj bi bila v tej mitski misli povsem drugačna od "vzhodne«, od tod tudi rasistično prepričanje o tujcih kot »varnostni grožnji«. Evrocentrični diskurz Evropejce (vključno z ZDA) slika kot demokratične, migrante in begunce pa kot nedemokratične, ne ločuje med posamezniki in režimi in ne upošteva izrednega položaja ljudi, ki so izgubili dom, jim preti politično motivirano mučenje, prisilna mobilizacija, lakota in smrt zaradi pomanjkanja zdravstvene oskrbe in so na begu v negotovo prihodnost. Tako je Reporter zapisal:

Na nevarnost je 25. avgusta v kolumni za Reporter opozoril tudi nekdanji direktor Sove Damir Črnčec, ki je ob tem pozval, da se moramo tega zavedati in ukrepati, še predno bo prepozno. Posledice nezakonite migracije pretežno islamske populacije, ki zavrača evropske demokratične vrednote, je primerjal s tistimi, ki so jih v 16. stoletju povzročili turški vpadi. (Kršinar 2015)

Ker so današnje množične migracije povezane z globalnim liberalnim kapitalizmom, ki "spreminja cone osiromašenja v cone vojne in vice versa (Balibar 2015: 211), ni zanemarljivo, da je del evrocentrističnega konstrukta tudi prepričanje, da je kapitalizem "poenotil« Evropo in »da je bil kapitalistični čudež lahko samo evropski« (Amin 2009: 58). V resnici je kapitalizem države polariziral, poglobil neenakosti, jih razdelil na center in periferijo, in sicer tako temeljito, da države periferije niso mogle nadoknaditi razlik v razvoju v primerjavi s t. i. razvitimi državami. Danes so te razlike še bolj očitne. Izginil pa ni niti konstrukt, da so vzroki za razlike in neenakosti med državami izključno »notranji«.

6 Izbrani primeri člankov so del širše analize obeh tiskanih medijev v času »balkanske begunske poti«. Članke (skupaj 93) je zbrala in sortirala Simona Šivec, študentka podiplomskega študija Socialna pravičnost in vključevanje na področju hendikepa, etničnosti in spola (2015/2016) na Fakulteti za socialno delo.

7 Ni torej čudno, da ljudje ne vedo, da sirski begunci niso zgolj muslimani, temveč tudi katoličani, ali pa da nekateri zavračajo religioznost kot singularno identiteto (Sen 2009). 
Od te konstrukcije »Vzhoda« ni več daleč do današnje medijske kulturalizacije, ki v ljudeh z Bližnjega vzhoda, ene od zibelk evropske kulture, vidi krvoločneže:

Medtem so se otroci, ki so jim policisti in vojaki pustili, da skačejo naokoli po prašni cesti ali polju, igrali. Na trenutke je bila njihova igra zelo značilna za muslimane z Bližnjega vzhoda - med sabo so si metali manjše kamenje. Trenirati je treba že zelo zgodaj, kamenjanje ljudi je med muslimani izredno priljubljeno. (Biščak 2015)

Navezujoč se na Amina, Mastnak (2009) poudarja, da je evrocentizem prepleten z evropskim osvajanjem sveta, ki je bil resnični vzrok nastanka kapitalizma. Evrocentrizem, kot ga poznamo danes, se je izostril v poznem 15. stoletju, ko se je pojavilo kolektivno zavedanje nečesa, kar se je poimenovalo »Evropa« kot politična skupnost (prav tam: 181). Srednji vek torej še ni poznal »Evrope«, ideja o njej kot o fizičnem in duhovnem prostoru zahodne, latinske in krščanske kolektivne identitete pa se je razvila po turški osvojitvi Konstantinopla leta 1453 . Tedaj so se pojavili klici po nujnosti ubranitve »Evrope« pred Turki, neverniki. V enem od člankov v tedniku Reporter je ta kolektivni spomin, ki je evropsko identiteto konstruiral v binarnem nasprotju kristjani : neverniki/muslimani in ki so ga s pomočjo pisnih virov negovale številne generacije, ponovno vzniknil v podobi spopada religij:

Kako pripravljeni so prihajajoči muslimani na sožitje z našo, evropsko kulturo pa pokaže naslednji primer: $\mathrm{v}$ do zadnjega kotička napolnjenem čolnu so se vozili muslimanski in katoliški begunci iz Libije. Ko so prišli na odprto morje, pa so muslimani pometali vse katoličane v morje. (Starič 2015)

Mastnak poudarja, da je bila Evropa »iznajdena v enotnem nasprotovanju zahodnih kristjanov Turkom, ki so bili obenem realna sovražna politična sila in simbolna podoba muslimanskega sovražnika« (2009: 182). Z drugimi besedami, »muslimanski problem« je dejavno prisoten $v$ jedru zgodovinske konstitucije evrocentrizma« (prav tam), podobo sovražnega Turka pa so v času »balkanske begunske poti« mediji ponovno oživili:

Cilj džihadistov je popolno uničenje zahodne civilizacije, kar pa jim na srečo ne bo uspelo. Že v zgodovini se je dogajalo pri nas poznano nasilje Turkov, ki so vpadali v naše kraje z znanimi ukrivljenimi sabljami, znak muslimanov za uničevanje ljudi, in pobijali, zažigali, posiljevali ter kradli otroke, ki so jih potem vzgajali v janičarje. (Štokelj 2015)

Horde nepovabljenih in nezakonitih novodobnih Turkov derejo na slovensko ozemlje, kot da gre za nekaj najbolj normalnega, in za sabo puščajo tone odpadkov (samo na Brežiškem v enem tednu več kot sto ton!). [...] Lahko od takšnih ljudi pričakujemo, da bodo kot prebivalci Evrope spoštovali njeno civilizacijo, kulturo? (Klemenčič 2015)

Mediji, ki ustvarjajo »resnico « in reproducirajo interes politike, krepijo obstoječe vzhodnoevropske nacionalizme tako, da na najrazličnejše načine kulturalizirajo begunce. Objektivizacija Drugega brez pripravljenosti razumeti, iz kakšnih okolij nasilja in trpljenja bežijo begunci, je nujna, da se sprosti socialna sposobnost drugemu prizadejati bolečino. Feldman (2015) govori o kulturni anesteziji, ki je stanje, ko se družba na kolektivni ravni ni sposobna soočiti z bolečino drugega in je ne more prenesti. 
Desno usmerjeni mediji so tudi osebne zgodbe ljudi, ki govorijo o skrajni stiski in obupu, prevajali v primere zgodb sumljivih tujcev. Nekateri begunci so v obupu, da jih ne bi vrnili v državo vstopa in nato nazaj domov, nasprotovali dajanju prstnih odtisov: "Migrant, ki zavrača dajanje prstnih odtisov, je oseba s slabimi nameni« (Glucks 2015). Ljudi, ki trpijo, pa naj gre za otroke ali odrasle, se spremeni ne samo v osebe, ki so sposobne nasilnih dejanj, ampak kar v ljudi, katerih obstoj sam je že orožje:

Vsak moker in premražen migrantski otrok na naši meji, katerega fotografijo objavijo mediji, je topovski izstrelek, vsaka množica iz muslimanskega sveta, ki predre policijski kordon, je zmagovita ofenziva. Orožje zoper Evropsko unijo je masa ljudi, ki jo je do zdaj uspešno ustavil samo madžarski premier Viktor Orban. (Glucks 2015)

Še več, pomanjkanje empatije in nerazumevanje zgodovine vojn na območjih, s katerih prihajajo migranti, pomeni zanikanje nesmiselnosti bojevanja za tiste, ki so z begom v Evropo zavrnili pobijanje ljudi bodisi na strani vladnih bodisi na strani lokalnih, paravojaških ali mednarodnih sil. Nesmiselne vojne rasistični diskurz spreminja v ideologijo domoljubne vojne. Tako so mediji mladim moškim, ki so pobegnili pred zapori, mučenjem in vojno, ki so jo preživljali od leta 2011, nekateri pa so se v vojnah že rodili, očitali nekakšno dezerterstvo in pomanjkanje domoljubja:

Sirci so medtem množično zapuščali svoje domove. Bežali so pred bombami Asadovega režima in pred verskimi blazneži, a nikomur od teh mladih bežečih fantov ni padlo na pamet, da bi se boril za svojo domovino. Tak odnos bodo zagotovo imeli tudi do države, ki jim bo ponudila zatočišče in jih sprejela za svoje. (Biščak 2015)

Konstruiranje ideje o domoljubni vojni je način, da se travmam, socialnemu trpljenju, razpadu skupnosti in množičnim smrtim pripiše smisel in opraviči nesmiselno vojno. Socialna amnezija ali izbris spomina, o katerih govori Feldman (2015), pa sta še bolj očitna v zahodni ideologiji opravičevanj mednarodnih intervencij, ki se imenujejo kar 'pravične vojne' (just wars), 'preventivne vojne' (preventatives wars) ali 'vojne proti terorizmu' (war on terrorism). Postsocialistične države, ki so bile, kot pokažem v nadaljevanju, same objekt evrocentrizma (ob vstopu v Evropsko unijo značilna formulacija, da bodo s tem "postale del Evrope«), so se na begunce odzvale prav $z$ evrocentrizmom, s pomanjkanjem empatije, kulturno anestezijo in z zgodovinsko amnezijo lastnih izkušenj vojn, begunstva in travm po letu 1991.

\section{BALKANSKA BEGUNSKA POT KOT DEL REVITALIZACIJE KONSTRUKTA O BALKANU}

Pred namestitvijo v namestitvene centre po različnih državah Evropske unije morajo ljudje meje šele prestopiti. Meje so prostori zavrnitev, selekcije, policijske brutalnosti, depersonalizacije (spanje na prostem, čakanje v vrsti dolge ure, čakanje v vrsti na dežju, večurna hoja, pomanjkanje sanitarij, hranjenje ljudi skozi žico ipd.) in tudi prostori pogajanj, odpora in solidarnosti (Zorn 2016). O prepletenosti navedenega priča dnevniški zapis z mejnega prehoda Obrežje/Bregana, 20. septembra 2015: 
Na meji med Slovenijo in Hrvaško je okoli 100 šotorov. Ljudje so iz Hrvaške, Slovenije, Avstrije, poročevalec s Portugalske, televizijska ekipa iz Nemčije, Sirci, Afganistanci in drugi. Postavljeno je še nekaj večjih šotorov, kjer je mogoče dobiti vodo, hrano, obleke in prvo pomoč. Kar vidim, me spominja na bolšji trg z gomilami oblek, kuhane hrane in ljudi. Takšne meje nisem vajena. Postala je prostor čakanja in negotovosti, pa tudi srečevanj, organiziranih dogodkov, prostor načrtov za prihodnost in predvsem izmenjevanja informacij. Ljudje ne razumejo, zakaj jih je policija zadržala v tem zaporu na prostem, še manj vedo, koliko časa bodo morali prebiti tu. Nekateri so tu že četrti dan. Kaj se bo zgodilo, ko bo prišla nova skupina in bodo imele spet prednost ženske z otroki, ki jih bodo ločili od moških in z avtobusi poslali naprej v Slovenijo? Vsak razmišlja, kdaj bo prišel na vrsto. Ljudje me sprašujejo, ali sta Slovenija in Hrvaška v vojni, ker je na meji toliko vojakov? Grozno se počutim, ko jim povem, da je to schengenska meja, in ko jim zamolčim, da je bila narejena prav za njih, da jih zaustavi. (Zorn 2016: 2)

"Ali sta Slovenija in Hrvaška v vojni, ker je na meji toliko vojakov«, se zdi kot vprašanje naivnega začudenja, ki pa je $\mathrm{v}$ resnici posledica travme in retravmatizacije, ki dobi obliko nevedenja. Cathy Caruth (1996) poudarja, da travma onemogoča celotno registracijo dogodka. Travmatizirana oseba ne more v celoti in naenkrat doumeti in občutiti travmatičnega dogodka, zato travmatično izkušnjo doživlja z zamikom. Travmatičnost dogodka preprečuje vedenje in povzroča ne-vedenje, ne-razumevanje. Dori Laub (1992) govori o kognitivnem zoženju, ki pri travmi omeji tisto, kar lahko oseba opazi ali čuti. Prav to pa je preventivna narava travmatičnega spomina, ki ima značilnost zanikanja ali potlačitve. Tudi v spominih ljudi, ki so preživeli različne oblike institucionalnega nasilja v psihiatričnih bolnicah ali zavodih za hendikepirane, se ponavlja vprašanje, ki hkrati to ni: «ne razumem, zakaj «; »nikoli nisem mogla razumeti, zakaj jim je bilo ponoči tako težko priti in nas obrniti okoli« (Zaviršek 2000: 143). Tudi med begunci se travmatični dogodek ponavlja v obliki vprašanja »zakaj«: »Zakaj nas ne spustijo čez mejo, saj nismo kriminalci?«; »Zakaj nas zapirajo, saj nismo nikomur nič naredili? « Vprašanja, ki ostanejo brez odgovora, kažejo na nemoč osebe, da bi, kot pokaže Dori Laub (1992), pričala sama zase, da bi bila 'priča od znotraj' (witness from within).

A obenem begunce in migrante razmere na meji upravičeno spominjajo na vojno. Vojna, ki je del administrativnega aparata države, kot pokaže Foucault (1997), se tako vse bolj razteza v civilno sfero, na vaške travnike, in postaja del ideologije varovanja tistega, kar se "potencialno lahko zgodi« (Feldman 2015: 72). Različne prakse vladnosti, ki se prikazujejo kot nemilitantne, pacifistične, pogodbene, pravne, so v resnici del vojnega aparata. S postavitvami ograj, zidov, rezalnih in bodečih žic pa je prostora za pogajanja vse manj. Nasprotno, oživeli so stari stereotipi, kot na primer poimenovanje »balkanska begunska pot", sintagma, ki oživlja stereotip o Balkanu kot delu Evrope, ki je zgodovinsko »markiran « kot evropska periferija. Evrocentrizem se tu pojavi v dveh plasteh, kot kulturalizem zahodnega sveta do periferije in kot odnos periferije do nezaželenih prišlekov.

Med vojnami na ozemlju Jugoslavije v devetdesetih letih 20. stoletja je Balkan postal sinonim za nacionalizme in politične ter socialne konflikte (čeprav v vojne med nekdanjimi jugoslovanskimi republikami niso bile vključene Grčija, Bolgarija, Romunija, Albanija 
in Turčija, ki se jih prav tako uvršča na Balkan). ${ }^{8}$ Kljub temu je z besedo »balkanizacija« zahodni svet začel poimenovati razmere, za katere so bili značilni družbena fragmentacija, nesmiselni konflikti in porušena socialna kohezija. ${ }^{9}$ Todorova $(1997 / 2009 ; 2015)$ je zgodovinski proces marginalizacije in stereotipizacije Balkana, ki je v stoletjih postal nasprotje Evrope, poimenovala balkanizem; ta se prenaša $\mathrm{z}$ novinarskimi, s političnimi in $\mathrm{z}$ literarnimi viri.

»Balkanska begunska pot« je danes del balkanizma, njegova revitalizacija in nova zgodovinska pojavna oblika, ki obuja stare stereotipe o »hordah barbarov « ${ }^{10}$ (Turkov, Slovanov, Vzhodnoevropejcev), ki z Vzhoda preplavljajo Evropo in s tujo religijo in tujimi navadami rušijo zahodno demokracijo, harmonijo in blaginjo.

Balkan je torej še danes zrcalni obraz Zahoda, njegova konstrukcija in projekcijsko platno, na katerega Zahod projicira vse, česar se pri sebi želi znebiti. S pojavom »balkanske begunske poti« lahko ta socialnopsihološki proces vzamemo kar dobesedno, saj Zahod na Balkan ne odlaga zgolj predstav o lenih, koruptivnih, manj sposobnih ljudeh in lastnih strahov o ekonomski krizi, ki zajema vse širše sloje svetovnega prebivalstva, temveč vanj dejansko odlaga ljudi, ki se jih hoče znebiti oziroma jih noče sprejeti. ${ }^{11}$ Turčija in Grčija sta postali državi - zapora, saj so ljudje, ki nimajo denarja, da bi s pomočjo tihotapskih poti nadaljevali pot v druge evropske države, ujeti v njih. Zahod tako potrebuje Balkan zaradi dvojega, da se z njegovim obstojem sam vzpostavlja kot kriterij razvitosti in demokratičnosti ${ }^{12}$ in da brani njegove namišljene meje. Ko je Avstrija začela načrtovali ograjo na slovensko-avstrijski meji, jo je decembra 2015 postavila na meji z Balkanom (štiri kilometre). Balkan je postal vratar Zahoda, varuh »zlate kletke«, če parafraziramo pesnico Sylvio Plath. Ne gre zgolj za simbolno funkcijo vratarja v kafkovskem pomenu, temveč dejansko

8 Zaradi vojn na Balkanu ni ostalo veliko od multietničnih teritorijev in še manj od njegove multiplicitete, saj imamo danes praviloma etnično homogene države in njihove institucije. Še več, večina držav na Balkanu je postavila zidove, ograje ali bodeče žice vsaj na eni od svojih meja. Grčija je že leta 2012 postavila $12 \mathrm{~km}$ dolgo ograjo s Turčijo, Madžarska je julija 2015 začela postavljati žično ograjo s Srbijo $(175 \mathrm{~km})$ in nekaj mesecev pozneje s Hrvaško $(348 \mathrm{~km})$, leta 2016 pa je pripravila vse za gradnjo meje z Romunijo. Novembra 2015 je Makedonija začela postavljati ograjo na meji z Grčijo, Slovenija je novembra 2015 postavila žično ograjo na svoji južni meji s Hrvaško. Bolgarija je leta 2014 začela graditi trimetrski zid, obdan z bodečo žico, na meji s Turčijo. Ta je bil junija 2016 dolg že $146 \mathrm{~km}$, kar pomeni, da je med državama neprehodna betonska meja, ki naj bi potekala vzdolž celotne meje $(166 \mathrm{~km})$. Turčija pa je postavila betonski zid na meji s Sirijo, ki ga postopoma gradi vzdolž $900 \mathrm{~km}$ dolge meje.

9 Ker besede "potujejo«, je deloma cinično, deloma pa šaljivo, da je bolgarska teoretičarka Miglena Nikolčina Združeno kraljestvo po brexitu označila kar z »balkanizacija Združenega kraljestva« (Krečič 2016).

10 Danes je besedo »horda« zamenjala modernejša »cunami«; tako mediji pišejo o »begunskem cunamiju«.

11 Septembra 2016 je bilo v Grčiji okoli 60.000 ljudi, ki so tam »obtičali«, Turčija ima 2,5 milijona beguncev, kar je največ v Evropi, ki so ostali ujeti v državi, ko je ta spomladi 2016 sklenila dogovor o zadrževanju beguncev znotraj svojih meja v zameno za vizumsko liberalizacijo (Žerjavič 2016; UNHCR Global Report 2015).

12 Z izvolitvijo Donalda Trumpa za predsednika ZDA novembra 2016 se je tradicionalna polarizacija med demokratičnim Zahodom vs nedemokratičnim Vzhodom radikalno zamajala. 
funkcionira kot teritorij, ki naj prepreči vstop beguncem in migrantom. ${ }^{13}$ Takšen režim je ustvarila že uradna politika Evropske unije, ko je vzpostavila enoten nadzor na svojih zunanjih mejah (schengenski nadzor) in sprejela Dublinski sporazum, ki določa, da se migrante, ki ne dobijo političnega azila, vrne v prvo varno državo, v katero so vstopili (najpogosteje v Madžarsko, Bolgarijo, Grčijo, Turčijo, Italijo). Zgodovinska funkcija Balkana je torej trojna. Z njim Zahod ohranja svoje simbolne in ekonomske privilegije; je koristen kot grožnja, ki naj konsolidira večinsko prebivalstvo doma in argumentira povečanje policijskega in vojaškega nadzora $\mathrm{v}$ zahodnih državah pod geslom varovanja državljanov; in tretjič, Zahod Balkan potrebuje kot branik, ki prebežnike zadržuje na svojih mejah.

Če je »balkanska begunska pot« oblika balkanizma, torej nadaljevanje strategije ustvarjanja in ohranjanja periferije Zahoda, pa so države Jugovzhodne Evrope na begunce in migrante prav tako odgovorile s kulturalizacijo, z evrocentrizmom in islamofobijo. Njihova socialna amnezija, povezana s travmatično izkušnjo lastne viktimizacije, je preprečila, da bi v ljudeh, ki bežijo pred vojno, terorjem, mučenjem in smrtjo ter jih zaustavljajo bodeče žice, videli same sebe. ${ }^{14}$

\section{NAMESTITVENI CENTRI KOT NADALJEVANJE "VELIKEGA ZAPIRANJA«}

Od epidemije gobavosti je postalo zapiranje ljudi v azile, zavode in bolnišnice zaporniškega tipa po Evropi ne le ponavljajoča se praksa, temveč strukturna oblika izključevanja Drugega (Foucault 2006/1961). Struktura zapiranja se je ohranila s politiko prostorov, v katere so bili naseljeni »odvečni« ljudje. Nekdanje hiralnice so postale vojašnice, vojašnice so postali zavodi za hendikepirane, nekdanje psihiatrične bolnišnice so postale namestitveni centri za migrante (Zaviršek 2015). Kot nekdaj, je treba tudi danes upravljanje ljudi poenostaviti in skriti. Sredozemski in jadranski otoki pa tudi otoki sredi Tihega oceana so postali mesta velikega zapiranja. Vladni namestitveni center za mlade brez spremstva, ki je v zadnjih letih deloval v mestu Mitilini na grškem otoku Lezbosu, ${ }^{15}$ so odprli v stavbi nekdanje psihiatrične bolnice, še prej pa je bila v njej bolnišnica za bolnike s tuberkulozo (Videmšek 2016: 76). V času Jugoslavije so na otokih gradili tako zapore (zloglasni zapor za politične zapornike na Golem otoku) kot psihiatrične bolnišnice in azile za hendikepirane (na Hrvaškem so bile psihiatrične bolnišnice na otokih Mljet, Rab in še delujoča na Ugljanu). Grške socialnovarstvene ustanove so na otok Leros pred desetletji v azil poslale na stotine hendikepiranih. Avstralska vlada je s 'pacifiško rešitvijo' (Pacific solution) že leta 2001 ljudi, zajete $\mathrm{v}$ bližini avstralske obale, začela nameščati v centre za tujce, ki so jih zgradili na majhnih otokih državne uprave Nauru in novogvinejskega otoka Manus (Briskman 2012). Na grških otokih je v'relokacijskih centrih' (t. i. hot spotih), kjer ljudje čakajo na premesti-

13 V novi zgodovinski konstelaciji je izostal pomemben del balkanističnega konstrukta, to je konstrukcija Balkana kot prostora užitka, dobre hrane, glasbe in nedela. Od leta 2015 so nekatere obmorske države Balkana povsem nezaželen turistični cilj.

14 Spomnimo se trpljenja ljudi, ki so pred drugo svetovno vojno odhajali kot ekonomski, po njej pa kot politični migranti, in štirih milijonov ljudi, ki so domove zaradi vojn na območju Jugoslavije zapustili po letu 1991.

15 Na Lezbos je samo leta 2009 prišlo 13.000 ljudi (Videmšek 2016a: 73). 
tev v druge države EU ali na deportacijo, in jih nekateri poimenujejo kar koncentracijska taborišča, saj v njih vladajo grozljive razmere (na otoku Hios na primer), ujetih okoli 9.420 beguncev in migrantov, $\mathrm{z}$ njihovim statusom pa se večinoma nihče ne ukvarja (Videmšek 2016a,b). Strukturna reprodukcija "populacij« in Drugega se poustvarja tako, da se nove in nove ljudi namešča v iste zavržene in stigmatizirane prostore. Foucault je pokazal, da je nova tehnologija oblasti od konca 17. stoletja postopoma iz ljudstva začela ustvarjati "populacije«, "politično telo« pa se je spremenilo v »biološko telo« (Foucault 2015/2004). Tehnologija oblasti je v obliki »biooblasti« prevzela skrb za življenje »populacij« in spremenila prejšnjo naravo skrbi, značilno za predkapitalistične oblastne strukture: »Starodavna pravica vzeti ali pustiti življenje odstopi mesto svoji na glavo obrnjeni podobi, ki označuje moderno biopolitiko in se izraža v obrazcu dati živeti in pustiti umreti« (Agamben 2005/1998: 60).

Meje so prvi prostor proizvajanja beguncev kot populacije, ki je podvržena biooblasti, saj se na mejah ljudi sortira na "upravičene« in "neupravičene« migrante, ekonomske in politične migrante, na tiste, ki dobijo status prosilca za azil, azilanta, imajo začasni status, so brez statusa, torej ilegalni itd. Proizvodnja "populacij(e)«, »drobljenje biološkega polja« (Foucault 2015/2004) zahteva nove prostore, kamor oblast namesti ljudi (v centre za tujce, azilne domove, namestitvene centre ipd.). Goffman $(1957,1961)$ je podobne prostore nekoč poimenoval totalne ustanove, za katere je bilo značilno nadzorovanje varovancev s strani zaposlenih in ustvarjanje institucionalne kulture, totalna ločenost zaprtih od večinskega prebivalstva, hierarhija med varovanci in socialna smrt. Proizvodnja populacij pa je hkrati tudi rez v "populacijo«, v kateri imajo nekateri državljanski status in drugi ne. Ideologijo "populacije" pri vsakdanjem upravljanju migracij s pridom uporabljata kulturalizem in kulturni rasizem: "PPonudimo jim konzerve, sadje, vodo, kruh, hrano pač, ki je primerna tej populaciji (poudarek D. Z.). In radi jo vzamejo,^ je povedala Zdenka Močnik, vodja brežiške izpostave uprave za zaščito in reševanje« (Šujić 2015b).

Vidik biopolitike »dati živeti« namesto "pustiti umreti« so pri upravljanju migracij zdravstveni pregledi. Migrante, ki pridejo iz Turčije v Grčijo, policisti aretirajo ${ }^{16}$ in jih nato odpeljejo v bolnišnico, kjer jih pregledajo, ali ne prinašajo nalezljivih bolezni. Potem jih $\mathrm{s}$ trajektom odpeljejo v namestitveni center na otok Hios (Videmšek 2016a: 73). Biopolitični stroj oblasti geografski prostor, to je morsko mejo med državama, spremeni v absolutni biopolitični prostor, kjer potekajo selekcija, sortiranje in zdravstveni pregled "populacije«, ki naj prepreči okužbe in bolezni domačega prebivalstva. Tako biooblast v sistem »omogočanja življenja« uvede rasizem in, kot opozori Agamben, v biološki kontinuum zariše cezure in uvaja načelo vojne (Agamben 2005/1998: 61). Za begunce se ob prestopu nove meje začne nova vojna.

Trdim, da imamo v 21. stoletju opraviti s procesi, znanimi iz obdobja hitro razvijajočega se kapitalizma od srede 17. stoletja, ko so revne, hendikepirane, nepreskrbljene, »moralno vprašljive « ljudi zapirali v polzaporniške medicinsko-administrativne institucije in ki so z uporabo biopolitike postali »populacije«. Če je bilo »veliko zapiranje« v norišnice, polzaprte ali zaprte zavode po večjih zahodnih mestih in pozneje po vsej Evropi in njenih kolonijah namenjeno konstrukciji in utrditvi ideje o normalnem in deviantnem, moralnem in nemoralnem, pravilnem in nepravilnem, je "veliko zapiranje« beguncev in migrantov

16 Videmšek opisuje, da je za migrante na tej poti najvarnejše, da, ko vidijo čoln policijske patrulje, poskačejo v vodo, saj jih bodo policisti iz vode rešili in potem aretirali (Videmšek 2016a: 73). 
z globalnega juga in evropske periferije namenjeno konstrukciji nove "populacije«, ki naj nadomesti hendikepirane, revne in norce, in to $\mathrm{z}$ namenom, da se struktura izključevanja ohrani z reprodukcijo Drugega. Obenem se s tem ohranjajo ekonomski in socialni privilegiji zahodnega sveta.

Kako rigorozno je bilo "veliko zapiranje« v 19. stoletju, opiše Foucault, ko pravi, da sta se samo v Parizu vsak stoti prebivalec ali prebivalka znašla za zapahi (2006/1961: 49). Kako vseobsežno in totalno je danes »veliko zapiranje« beguncev in migrantov, pa povedo podatki, da je na primer v namestitvenem centru Pagani v mestu Mitilini na Lezbosu živelo po 2.000 oseb naenkrat. Na italijanski Lampedusi je bil namestitveni center, imenovan kar »italijanski Guantanamo «, z več sto ljudi v prostorih, namenjenih veliko manjšemu številu oseb. Na grškem Hiosu je spalo po 17 oseb v eni sobi (prim. Videmšek 2016a). Nove institucije migrante in begunce ustvarjajo kot "populacijo« in obenem kot nevidne. Gre za policijsko-humanitarne prostore $\mathrm{z}$ disciplinskim načinom vodenja in s hierarhičnimi odnosi moči med upravljavci in zaprtimi in med zaprtimi samimi. Ko Bradol (2004) analizira današnjo mednarodno humanitarno pomoč, govori o »oboroženem humanitarizmu«, natanko tako pa lahko po vsem svetu poimenujemo tudi delovanje različnih institucij za begunce.

Če so torej "politično kulturo nevarnosti« (Foucault 2015/2004: 67) v 19. stoletju tvorili norci in "moralno izrojeni«, ki lahko okužijo posameznike, družine in celotni narod, je današnja "politična kultura nevarnosti« osredotočena na begunce, ki ogrožajo »naše družine«, skupnosti in ves zahodni svet. Za ljudi, prestrašenimi zaradi nepredvidljive »animalne« narave norcev, so postali ti pregovorna in mitologizirana grožnja tedaj, ko so jih zaprli, institucije pa dobrodošel ukrep, ki naj varuje večinsko populacijo pred nasiljem in kriminalom. To se danes dogaja beguncem, ki so postali simbol zunanje grožnje, to je terorizma.

Tudi institucije za migrante in begunce, kot je bilo nekoč značilno za norce, so urejene zunaj urbanih centrov, na obrobjih mest in manjših krajev, kar poceni njihov nadzor, ga naredi skritega in minimalizira stik migrantov z zunanjim svetom. ${ }^{17}$ Nekatere institucije za migrante in begunce so enoznačno represivne ustanove, kot na primer centri za tujce, ki jih je Slovenija ustanovila leta 2001 in jih poimenovala kar »centri za odstranjevanje tujcev«. Rasistično poimenovanje navaja na misel, da je tisto, kar je treba odstraniti, že samo po sebi škodljivo. Tudi poimenovanje »centri za tujce« je evfemizem, ki ga poznamo iz obdobij velikega zapiranja hendikepiranih (in pri nas ponekod še danes), ko so se institucije imenovale »sanatorij«, »dom» in »bolnišnica«. Oboji so »ne-prostori«, ker ne integrirajo drugih socialnih prostorov, pomenov, tradicij, običajev; so ne-simbolizirani in nimajo drugega namena in dejavnosti, kot sta izolacija in prepoved prostega gibanja (Kralj 2005: 180; Lipovec Čebron, Zorn 2016).

Institucionalizacija je doživela preobrat v 20. stoletju, ko je po zahodnih državah v različnih obdobjih, bodisi med obema svetovnima vojnama bodisi po drugi svetovni vojni, zaradi spoznanja, da so mnogi ljudje $\mathrm{v}$ azilih doživeli najrazličnejše zlorabe in zatiranja, $\mathrm{v}$ večjih prišlo do deinstitucionalizacije. Stigma, mortifikacija jaza, proizvodnja volatilnih teles, profesionalni paternalizem in druge oblike institucionalnega nasilja so bili ves čas del institucionalne pedagogizacije. Proces definiramo kot ukinjanje velikih ustanov in njihovo nadomeščanje $\mathrm{z}$ dovolj majhnimi, ljudem dostopnimi in trajnimi socialnimi servisi,

17 Namestitveni centri so danes tudi v mestnih jedrih (v Ljubljani na Kotnikovi ulici). V Berlinu, na primer, je center za nujno namestitev nastal sredi mesta na Osloer Strasse 23, kjer živi tudi sicer največ priseljencev. 
ki zadovoljujejo potrebe ljudi po pomoči, asistenci, zdravstvenih in socialnih storitvah, ne glede na obseg storitev, ki jih človek potrebuje. Ena od značilnosti deinstitucionalizacije je, da socialni in psihosocialni servisi sledijo ljudem, in ne obratno, da se ljudi namešča v ustanove glede na prazne kapacitete in njihovo razpoložljivost. V zaprti instituciji se generira hierarhična struktura ne zgolj med osebjem, ki varuje in nadzoruje zaprte, temveč tudi med zaprtimi osebami samimi. Priče v namestitvenih centrih za migrante in begunce govorijo o izkoriščanju šibkejših beguncev s strani močnejših; o povezavah med tihotapci, prodajalci belega blaga in o zlorabah in prodaji otrok. $\mathrm{V}$ postsocialističnih državah, kamor je modernizacija prišla $\mathrm{z}$ zamikom, je poznejša tudi deinstitucionalizacija, ki je v številnih državah šele v povojih (Zaviršek 2006, 2014, 2015). Hkrati z njo pa se krepi institucionalizacija migrantov in beguncev (Lipovec Čebron, Zorn 2016). Če je nekoč stultifera navis po rekah vozila norce v bližnja srednjeveška mesta ali na njihove robove, danes ponekod prebežnike imenujejo kar boatpeople ('ljudje v čolnih') (prim.: Briskman 2012) in jih izvažajo v države evropske periferije, na obrobja držav ali na odročne otoke. Trdim, da se umanjkanje demokratičnih procesov deinstitucionalizacije po državah Vzhodne in Zahodne Evrope odraža v podobnem »velikem zapiranju«: v Franciji je znana »džungla« v kraju Calaise, ZDA imajo velike centre za tujce $v$ Texasu itd. Nasprotno pa so v Italiji, znani po zgodnjem odpiranju psihiatričnih ustanov (proces, znan pod imenom Psichiatria Democratica) v začetku sedemdesetih let 20 . stoletja, ki je prineslo prave kulturne in socialne premike pri sprejemanja razlik, begunci in migranti navkljub desnemu populizmu Lige Nord sprejeti v skupnosti in ne živijo zaprti v begunskih centrih in drugih prostorih zajetja.

Tako kot so bili nekoč norci, katerih »naravo« so enačili z živalskostjo, v nekem smislu "varnostna grožnja", so danes to migranti in begunci, zato humanitarni procesi delujejo predvsem kot »preventiva«. Foucault (2015/2004: 39) je pokazal, da so kazenske institucije pred obdobjem moderne prakso pravičnosti izvajale s temeljnim vprašanjem »kaj si storil?« Moderno kaznovanje pa je vprašanje spremenilo v »kdo si?« (uporabljajoč različne psihološke, socialne in pedagoške postopke). Foucault poudarja, da vprašanje »kdo si?» kaznovalno funkcijo izrekanja pravičnosti nadomesti z izrekanjem resnice (prav tam). Režimi izrekanja resnice, ki so od 19. stoletja medicinski, psihološki, pedagoški, sortirajo ljudi glede na diagnoze in moralne posebnosti. V centrih za tujce zaprti migranti pogosto sprašujejo: »Zakaj nas držijo tukaj, saj nismo kriminalci!« A gre za napačno vprašanje, saj biooblasti ne zanima več, kaj je kdo storil, temveč kdo oseba je. Policija in drugi represivni aparati države, ki proizvajajo resnico, ves čas zastavljajo vprašanje »kdo si«?, ko poskušajo ugotoviti, od kod in zakaj oseba prihaja in ali je potencialna grožnja terorizma? Gre za vprašanje, »kaj bi človek lahko naredil«, ne, kaj je naredil, to pa je, kot je pokazal Feldman (2015) v svoji politični teoriji vojn, že vpisano v današnjo politiko "pravičnih vojn « ${ }^{18}$ Odnos zahodnih držav do sodobnih migrantov iz držav, iz katerih bežijo zaradi vojn, ekonomskega životarjenja ali tradicionalnih oblik nasilja nad posamezniki in družinami, je torej mogoče primerjati z ljudmi, ki so jih po evropskih mestih od konca 17. stoletja zaradi revščine, ekonomske neučinkovitosti ali moralne vprašljivosti zapirali v različne ustanove.

18 Mastnak (2009:184) je nekaj let pred balkansko begunsko potjo napisal, da se je v zadnjih desetletjih evrocentrizem premestil v ZDA in da je ameriška hegemonija v resnici nadaljevanje evrocentrizma $\mathrm{z}$ drugimi sredstvi. 


\section{ZAKLJUČEK}

Čeprav so se metafore, kot so »Evropa trdnjava« in »Evropa kot berlinski zid«, začele pojavljati že po letu 2000 (Petrović 2015: 105), je danes postalo povsem jasno, da begunci, ki pridejo na evropske meje in vstopijo v evropske države, ne vstopajo v prostore demokracije, liberalizma in svobode, temveč prestopajo prag prostora, kjer jih čakajo identiteta Drugega in ne-prostori. »Oboroženi humanitarizem« se manifestira v militarizaciji nacionalnih meja, medijski demonizaciji in prostorski segregaciji. Ti procesi spominjajo na Foucaultovo misel, da je v liberalizmu svoboda nekaj, »kar se v slehernem trenutku proizvaja" (2015/2004: 66): "Liberalizem ni nekaj, kar svobodo priznava. Liberalizem se ponuja kot nekaj, kar svobodo v slehernem trenutku izdeluje, vzbuja in proizvaja, seveda skupaj s [celo množico] prisil in problemov glede stroškov, ki jih to izdelovanje zahteva.«

Tako Evropa danes proizvaja begunce in namestitvene centre, še več, proizvaja regije in države, ki postajajo velike totalne institucije, kamor druge države s svojih ozemelj »vračajo « migrante, od tam pa ljudje, kot pravi Agamben (2005), »ki prenesejo vse, kar zmorejo prenesti« in jih to dela neljudi, ne morejo nikamor več. Zato je potrebna deinstitucionalizacija begunskih prihodov in begunskih življenj, saj se v nasprotnem primeru krepijo oblike nedovoljene trgovine $\mathrm{z}$ ljudmi in tihotapstva, kršene so temeljne človekove pravice, socialna distanca med ljudmi pa se vse bolj poglablja. Za preživetje ideje človeškosti je treba svet videti kot enovit prostor ljudi, naravnih virov in dobrin, ga historizirati in tudi v vsakdanjem življenju zagotoviti, da je prostor vseh, ne zgolj ekonomsko privilegiranih. Drugače bo stultifera navis, 'ladja norcev', še naprej plula in odlagala ljudi na neznane otoke, kjer bodo ob javnem molku tudi sami počasi utihnili in izginili.

\section{LITERATURA}

Agamben, Giorgio (2005/1998). Kar ostaja od Auschwitza: Arhiv in priča (Homo sacer III). Ljubljana: Založba ZRC SAZU.

Amin, Samir (2009/1988). Evrocentrizem: Kritika neke ideologije. Ljubljana: Sophia.

Balibar, Étienne (2015). Evropa in begunci: Demografska širitev. Časopis za kritiko znanosti $43,262,207-215$.

Bradol, Jean Herve (2004). The Sacrificial International Order and Humanitarian Action. In the Shadow of 'Just Wars' Violence, Politics and Humanitarian Action (ur. Fabrice Weissman). London: Hurst and Company, 1-24.

Briskman, Linda (2012). Protecting Vulnerable Asylum seekers: Human Rights in Australia. Social Dialogue Magazine 3/3, 24-31.

Caruth, Cathy (1996). Unclaimed Experience: Trauma, Narrative, and History. Baltimore: John Hopkins University.

Feldman, Allen (2015). Archives of Insensible: Of War, Photopolitics and Dead memory. Chicago: University of Chicago Press.

Foucault, Michel (1980). Power/Knowledge: Selected interviews \& other writings 1972-1977 (ur. Colin Gordon). New York: Pantheon Books.

Foucault, Michel (1997). Society Must be Defended. Lectures at the Collège de France, 19751976 (ur. Mauro Bertani, Allesandro Fontana, Arnold I. Davidson). New York: Picador, $13-63$. 
Foucault, Michel (2006/1961). History of Madness. Abingdon: Routledge.

Foucault, Michel (2015/2004). Rojstvo biopolitike. Kurz na College de France: 1978-1979. Ljubljana: Krtina.

Goffman, Erving (1957). Characteristics of total institutions: Symposium on preventative and social psychiatry. Washington: Government Printing Office.

Goffman, Erving (1961). Asylums: Essays on the Social Situation of Mental Patients and other Inmates. New York: Anchor Books.

Kralj, Ana (2005). Zapori za revne, taborišča za migrante? Socialno delo 44/3, 173-186.

Laub, Dori (1992). An Event without a Witness: Truth, Testimony and Survival. Testimony (ur. Shoshana Felman, Dori Laub). New York: Routledge.

Lipovec Čebron, Uršula, Zorn, Jelka (2016). Avtonomija in nadzor migracij v evropskih "tamponskih conah«. Dve domovini / Two Homelands 43, 61-75.

Mastnak, Tomaž (2009). Aminov Evrocentrizem: Revizija. Evrocentrizem (ur. Samir Amin). Ljubljana: Sophia, 179-185.

Pajnik, Mojca, Lesjak Tušek, Petra, Gregorčič, Marta (2001). Prebežniki, kdo ste? Ljubljana: Mirovni Inštitut.

Petrović, Tanja (2015). On the Way to Europe: EU Methapors and Political Imagination of the Western Balkans. Welcome to the desert of Post-Socialism: Radical Politics after Yugoslavia (ur. Srećko Horvat, Igor Štiks). London: Verso, 103- 122.

Sen, Amartya (2009). Identiteta in nasilje: Iluzija usode. Ljubljana: Sophia.

Todorova, Maria (2015). Re-imagining the Balkans. Welcome to the desert of Post-Socialism. Radical Politics after Yugoslavia (ur. Srećko Horvat, Igor Štiks). New York, London: Verso, 85-102.

Videmšek, Boštjan (2016a). Na begu. Moderni eksodus (2005-2016): Z begunci in migranti na poti proti obljubljenim deželam. Ljubljana: Umco.

Zorn, Jelka (2008). Ljudje brez pravice do pravic in vloga socialnega dela. Socialno delo $47 / 3-6,115-132$.

Zorn, Jelka (2016). Social work with refugees at the Schengen border: »... but they are the same people as we are«. Critical and Radical Social Work 20, http://dx.doi.org/10.1332/ 204986016X14525991940960 (20. 8. 2016).

Zaviršek, Darja (2000). Hendikep kot kulturna travma. Ljubljana: cf. ${ }^{*}$

Zaviršek, Darja (2006). Disabled women everyday citizenship rights in East Europe examples from Slovenia. Women and citizenship in Central and Eastern Europe (ur. Jasmina Lukić, Joanna Regulska, Darja Zaviršek). Aldershot: Ashgate, 62-87.

Zaviršek, Darja (2014). 'Those Who Do Not Work Shall Not Eat!' A Comparative Perspective on the Ideology of Work within Eastern European Disability Discourses. Disability in Eastern Europe and the Former Soviet Union (ur. Michael Rasell, Elena Iarskaia-Smirnova). Abingdon: Routledge, 184-203.

Zaviršek, Darja (2015). Anthropology, Social Work and Disability Studies: Researching Diversity in Eastern Europe. Ethnologie und Soziale Arbeit: Fremde Disziplinen, gemeinsame Fragen? (ur. Magnus Treiber, Nicolas Griessmeier, Christian Heider). Opladen: Budrich UniPress,107-132. 


\section{ANALIZIRANI VIRI}

Biščak, Jože (2015). Milijoni na poti. Reporter, 28. 9.

Biščak, Jože (2015). To se ne bo dobro končalo. Reporter, 2. 11.

Glucks, Nenad (2015). Vojna, v kateri je orožje masa ljudi. Reporter, 26.10.

Glucks, Nenad (2015). Skrajni čas je, da Slovenija popolnoma zapre južno mejo. Reporter, 23. 11.

Kršinar, Igor (2015). Odprte meje za teroriste. Reporter, 23. 11.

Klemenčič, Ivan (2015). Zaščitna ograja na slovenski schengenski meji bi že morala stati. Reporter, 9. 11.

Krečič, Jela, (2016). Treba je tvegati in si zamisliti utopijo. Delo, Sobotna priloga, 6. 8.

Preac, Gregor (2015). Iluzija vsega - je migrantstvo resnično? Reporter, 16. 11.

Starič, Peter (2015). Kako zajeziti poplavo beguncev. Reporter, 14. 9.

Šuljič, Tomica 2015a). Begunci so že zasedli Brežice. Slovenske novice, 19. 9.

Šuljić, Tomica (2015b). Islamski skrajneži tudi v Rigoncah! Slovenske novice, 17. 11.

Štokelj, Silvan (2015). Evropa trepeta pred džihadisti, vendar se prebuja! Reporter, 14. 12.

Videmšek, Boštjan (2016b). Evropska dvoličnost in turška brezkompromisnost, Delo, 2. 8.

Žerjavič, Peter (2016). Turčija bi izsiljevala, Evropa se ne da. Delo, 3. 9. 


\section{SUMMARY}

\section{"STULTIFERA NAVIS" ON THE BALKAN REFUGEES ROUTE Darja ZAVIRŠEK}

In 2015 1,015 million persons who fled from Syria, Afganistan and Iraq to the western and northern countries took either the Mediterranean or the Balkan refugee routes. The latter was different from all other migrant footpaths in the last decades due to the migration corridor which existed from August 2015 until early 2016 and was relatively free of surveillance for people to cross the borders and to move. With the increased number of refugees the Balkan states increased the militarization of the borders with the fences, razor wires, collection centres and hot spots. The article focuses on one dimension of the management of migration which is the institutionalisation of migrants and refugees in collection centres and hot spots, asylum and detention centres. The well-known processes of the "big confinement", biopolitics and the creation of "populations" are today pervaded with the ideologies of eurocentrism, culturalisation and cultural racism widely used by the media. An important part of the "management of migration" is the institutionalisation of people who flee from economic devastation and wars. Compared with the processes of spatial segregation of the disabled and people with mental health problems in the past, one can conclude that while the deinstitutionalisation has become a democratic norm for some people, an increase of the institutionalisation of migrants and refugees takes place. The lack of the democratic reflection about global interconnectedness of people and causes of economic scarcity and wars, bring about the confinement of new "populations" on a large scale, caused by the biopolitics of the nation states. Instead of the construction of the refugees as the national threat, health risk and cultural othering, the measures of deinstitutionalisation and depathologisation of the refugees' lives are needed. During the Balkan refugee route local population gradually increased their negative sentiments against refugees and media produced and reproduced very negative images of the migrant people. The old-fashion images of the "Turks" who are going to violate the Balkan population again were used by the media to support the militarization of the borders. In the western countries the image of the Balkan refugee route supported the processes of the re-emerging of balkanism and the process of turning the Balkan semi-periphery into an actual tampon-zone and the prison-like territory where the West not only projects its fantasies of the economic and moral superiority but pushes back real people whom the West doesn't want to receive. 